\title{
Periodontal condition and recurrence of periodontitis associated with alcohol consumption in periodontal maintenance therapy
}

\author{
Fernando-Oliveira Costa ${ }^{1}$, José-Roberto Cortelli ${ }^{2}$, Adriana-Moreira Costa ${ }^{3}$, Rafael-Paschoal-Esteves Lima ${ }^{1}$, \\ Sheila-Cavalca Corteli ${ }^{2}$, Luís-Otávio-Miranda Cota ${ }^{1}$
}

\author{
${ }^{1}$ Department of Dental Clinics, Oral Pathology, and Oral Surgery, School of Dentistry, Federal University of Minas Gerais, Belo \\ Horizonte, Minas Gerais, Brazil \\ ${ }^{2}$ School of Dentistry, Department of Periodontology, Federal University of Minas Gerais, Brazil \\ ${ }^{3}$ Newton Paiva Institute, Faculty of Dentistry, Belo Horizonte, Minas Gerais, Brazil
}

Correspondence:

School of Dentistry, Department of Periodontology

Federal University of Minas Gerais

Antônio Carlos Avenue, 6627, Pampulha

PO Box 359 Zip Code 31270-901. Belo Horizonte

Minas Gerais - Brazil

focperio@uol.com.br

Costa FO, Cortelli JR, Costa AM, Lima RPE, Corteli SC, Cota LOM. Periodontal condition and recurrence of periodontitis associated with alcohol consumption in periodontal maintenance therapy. J Clin Exp Dent. 2020;12(2):e139-47.

http://www.medicinaoral.com/odo/volumenes/v12i2/jcedv12i2p139.pdf

\begin{tabular}{|c|}
\hline $\begin{array}{l}\text { Article Number: } 56166 \quad \text { http://www.medicinaoral.com/odo/indice.htm } \\
\text { (C) Medicina Oral S. L. C.I.F. B 96689336-eISSN: 1989-5488 } \\
\text { eMail: jced@jced.es } \\
\text { Indexed in: } \\
\quad \text { Pubmed } \\
\text { Pubmed Central } 囚(\text { PMC) } \\
\text { Scopus } \\
\text { DOI® System }\end{array}$ \\
\hline
\end{tabular}

\begin{abstract}
Background: This study followed individuals in periodontal maintenance therapy (PMT) over 6 years and longitudinally evaluated the effects of the frequency of alcohol consumption on the recurrence of periodontitis (RP).

Material and Methods: From a 6-year follow-up cohort study with 268 individuals under PMT, 142 patients who attended at least one PMT visit within 12 months were determined to be eligible. Based on their alcohol consumption, participants were categorized into 3 groups: none or occasional alcohol use (NA; $n=88$ ), moderate alcohol use $(\mathrm{MA} ; \mathrm{n}=26)$ and intense alcohol use (IA; $\mathrm{n}=24)$. Complete periodontal examination and alcohol consumption were evaluated at 2 times, T1 (after active periodontal therapy) and T2 (6 years).

Results: The frequencies of RP in the NA, MA and IA groups were $46.5 \%, 57.6 \%$, and $79.1 \%$, respectively. The following variables were significantly associated with RP in final multivariate logistic regression model: age $>50$ years old $(\mathrm{OR}=1.79 ; 95 \% \mathrm{CI} 1.42-2.91 ; p=0.002)$, current smoking $(\mathrm{OR}=2.42 ; 95 \% \mathrm{CI} 1.33-4.31 ; p=0.001)$, and intensive alcohol use $(\mathrm{OR}=1.96 ; 95 \% \mathrm{CI}: 1.37-2.64 ; p=0.024)$. Interaction between intensive alcohol use and smoking showed a high OR estimate of 3.15 (95\% CI 1.29-6.32) for RP.

Conclusions: IA individuals undergoing PMT presented worse periodontal condition, higher rates of RP and tooth loss when compared to NA individuals. Additionally, the interaction between intensive alcohol use and smoking significantly increased the risk for RP.
\end{abstract}

Key words: Periodontitis, alcohol consumption, maintenance, epidemiology. 


\section{Introduction}

Periodontitis is a non-communicable disease characterized by microbially-associated, host mediated inflammation resulting in loss of periodontal attachment and can lead to tooth loss (TL) (1). Periodontal disease onset and propagation happens through the dysbiosis of the commensal oral microbiota (dental plaque), which then interacts with the immune host defenses, leading to inflammation and disease (2). The severity of periodontitis depends on environmental and host risk factors, both modifiable (i.e. smoking, alcohol consumption, obesity, life style factors, social life status and unhealthy conditions) and non-modifiable (i.e. age and genetic susceptibility) (2).

Alcohol consumption as a risk factor has been studied in relation to a great variety of conditions since it is responsible for almost $4 \%$ of deaths worldwide and almost $5 \%$ of the global disease contingent (3). It is also an important cause of health inequalities among individuals under negative social impact, due to high cost and specific care demand (4). A great number of diseases and injuries are directly caused by alcohol consumption $(4,5)$.

In recent decades, observational and epidemiological studies (5-9) pointing to a potential association between alcohol consumption and the development and progression of periodontitis have increased. A recent systematic review (10) reported that studies evaluating this relation are numerous and comprise different designs, yet presenting conflicting data. Furthermore, the authors emphasized that more well-designed cohort studies are necessary to confirm this risk association.

Several studies have highlighted the benefits of periodontal maintenance therapy (PMT) to preserve the homeostasis of periodontal tissues obtained after active periodontal therapy (APT), performed through surgical and/or non-surgical procedures (11-14) However, without establishing a regular program of clinical re-evaluation, adequate biofilm control, and re-inforcement of oral hygiene instructions, the benefits of PMT could not be maintained and a higher risk for future recurrence of periodontitis (RP) $(12-14)$ and TL may surge $(14,15)$. Besides, no prospective PMT study has demonstrated the effect of the frequency of alcohol consumption on periodontal condition and RP.

The hypothesis under testing in the present study was that individuals with frequent alcohol consumption higher RP, $\mathrm{TL}$ and worse periodontal clinical condition during PMT. Therefore, the present study followed individuals in PMT for over 6 years and longitudinally evaluated the effects of the frequency of alcohol consumption on periodontal condition and RP.

\section{Material and Methods}

-Study Design and Sampling Strategy

Participants of the present prospective study were selected from an open cohort study with 268 individuals under a PMT program, who were monitored in a private dental clinic in the city of Belo Horizonte - Brazil, over 6 years of consecutive recall visits (from August 2006 to February 2016). The study was approved by the local ethical committee (protocol \#060/05) and a written informed consent was obtained from all participants. This study was reported in accordance with the STROBE statements guidelines.

Individuals that underwent APT (comprised of non-surgical and/or surgical procedures) were included in the study sample according to the following criteria: (a) diagnosis of moderate to advanced chronic periodontitis $(16,17)$ (excluding any possibility of aggressive periodontitis cases) - prior to APT, the presence of least 4 sites with probing depth (PD) $\geq 5 \mathrm{~mm}$ and clinical attachment loss (CAL) $\geq 3 \mathrm{~mm}$, bleeding on probing (BOP) and/or suppuration (SU), and radiographic evidence of bone loss; (b) completion of APT in a period of less than 4 months prior to entering the PMT program; and (c) at least 14 teeth in the oral cavity (12). It is noteworthy that, based on the new classification system of periodontal diseases, an update in periodontal status of the sample was performed and individuals were currently classified with moderate to severe periodontitis (1).

From the cohort study with 268 individuals under PMT, 138 individuals who attended at least one recall visit within 12 months during the study period and completed the questionnaires of alcohol consumption between T1 (data being recorded after the first PMT appointment) and T2 (final data being recorded at the last PMT appointment, e.g., after 6 years under PMT) were determined to be eligible, thus representing a convenience sample.

These individuals were then stratified according to the frequency of alcohol consumption by means of 2 questionnaires: CAGE (Cut down, Annoyed, Guilty, Eye-opener) proposed by Mayfield et al. (18) and validated by Masur and Monteiro (19) and AUDIT (Alcohol Use Disorders Identification Test) proposed by the World Health Organization) (20).

The AUDIT questionnaire (20) composes itself by 10 questions, having scores $>8$ indicating alcohol use problems. The CAGE questionnaire $(18,19)$ is made of four questions, having scores $\geq 2$ indicating alcohol dependence. In this manner, individuals were categorized according to AUDIT and CAGE scores in three groups: (1) none or occasional alcohol use - never used or frequency of use less than monthly, AUDIT and CAGE scores = 0 ; (2) moderate alcohol use - frequency of use 2-4 times a month, AUDIT score $\leq 8$ and CAGE score $=0$; (3) intense alcohol use - frequency of use $\geq 3$ times a week, AUDIT score $\geq 8$ and CAGE score $\geq 1$.

Therefore, participants were allocated into: NA group - none or ocasional alcohol use $(\mathrm{n}=88)$; MA group moderate alcohol use $(n=26)$; and IA group - intense alcohol use $(n=24)$. 
In order to verify the power of the sample in each group, a sample size calculation was performed considering PD changes $(>4 \mathrm{~mm})$ as the primary outcome for the recurrence of periodontitis (RP). Considering a significance level of $5 \%$, a study power of $80 \%$, a medium size effect $(0.50)$ and a $15 \%$ minimum difference between groups in relation to PD changes (mean values), a calculated number of at least 23 individuals per group was determined to be necessary.

-Data Collection

Baseline data was recorded after the first PMT appointment (T1) and the final data at the last PMT appointment, i.e., after 6 years under PMT (T2).
Parameters of plaque index (PI), PD, CAL, and BOP were recorded for all present teeth at 4 periodontal sites (mesial, distal, buccal, and lingual) with a manual periodontal probe (Hu-Friedy®, Chicago, USA).

Description of data collection and periodontal clinical procedures during all PMT visits were previously reported by Lorentz et al. (12) and Costa et al. (13).

These following variables were also collected: sex, age, family income, co-habitation status, educational level, smoking (29) and diabetes. The flowchart of sampling strategy and study evaluation times is displayed in figure 1.

Cohort with 268 individuals
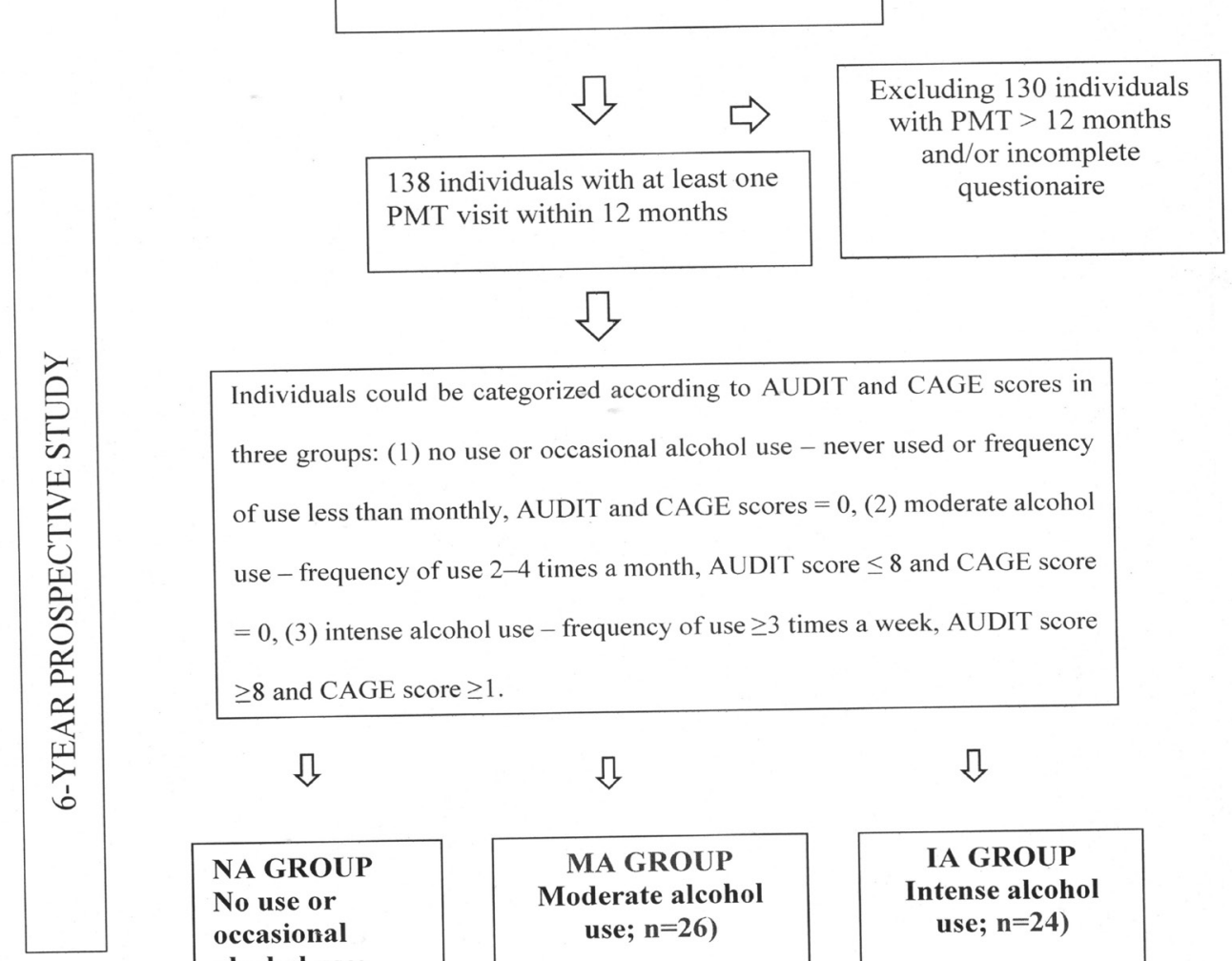

PMT visit within 12 months

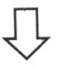

Individuals could be categorized according to AUDIT and CAGE scores in
three groups: ( 1 ) no use or occasional alcohol use - never used or frequency
of use less than monthly, AUDIT and CAGE scores $=0$, (2) moderate alcohol
use - frequency of use $2-4$ times a month, AUDIT score $\leq 8$ and CAGE score
$=0$, (3) intense alcohol use - frequency of use $\geq 3$ times a week, AUDIT score
$\geq 8$ and CAGE score $\geq 1$.

\section{$\sqrt{3}$}

NA GROUP
No use or
occasional
alcohol use;
$n=88)$

$\sqrt{2}$

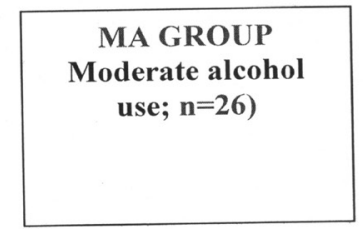

$\sqrt{3}$

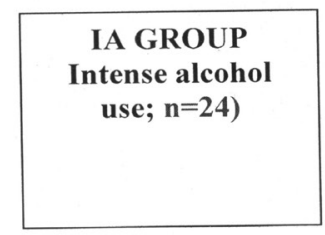

T1

(Assessment recorded after the first PMT appointment)
$\mathrm{T} 2$

(Assessment recorded after 6 years in PMT)

Fig. 1: Flowchart of sampling strategy and study evaluation times. 
-Periodontal monitoring

In each recall visit, the following procedures were performed: 1) interviews where demographic, biological and behavioral variables of interest were collected and confirmed through patient questionnaires, paying particular attention to those variables likely to change over time; 2) periodontal assessment through the evaluation of clinical parameters described in this paper; 3) application of disclosing agents and oral hygiene instructions, using the Bass technique and dental flossing or adjunctive methods (interdental brushing or water flossing; 4) mechanical debridement, when appropriate, including coronal prophylaxis and fluoride application. All procedures were performed by a group of trained and calibrated professionals.

-Determination of the recurrence of periodontitis (RP) and retreatment needs

Sites determined as having retreatment needs were the ones with RP: PD $>4 \mathrm{~mm}$ and $\mathrm{CAL} \geq 3 \mathrm{~mm}$, together with the persistence and/or presence of BOP and/or SU, during any of the subsequent recall evaluations $(13,22)$. PD changes were first re-treated with non-surgical procedures through mechanical subgingival debridement. After periodontal re-evaluation (45 to 60 days), sites with persistent $\mathrm{PD} \geq 5 \mathrm{~mm}$ and $\mathrm{CAL} \geq 3 \mathrm{~mm}$ underwent surgical procedures using the Widman modified flap technique (13).

-Inter- and intra-examiner agreement

Two trained and calibrated periodontists (FOC and EJPL) performed all the interviews, examinations, and clinical periodontal procedures. Evaluations of PD and CAL were performed and repeated within a 1-week interval in 10 individuals randomly selected from study groups at baseline and at T2. The kappa coefficients for intra- and inter-examiner agreement as well as intra-class correlation coefficients were greater than 0.87 . -Statistical analysis

Statistical analysis included a descriptive characterization of the sample according to variables of interest. Group comparisons by means of the Chi-squared and the Student $t$ tests were performed when appropriate. Multiple comparisons were performed by ANOVA and Welch test and adjusted by the Bonferroni correction post-hoc test.

A logistic regression analysis was performed to evaluate the association between RP and the independent predictor variables. All predictors presenting a p-value of 0.25 in the univariate analysis were included in the multivariate regression model. Variables were then manually removed step by step until the log-likelihood ratio test indicated that no variable should be removed. Variables were determined to be confounders if their removal from the model made changes greater than $15 \%$ in the $\mathrm{B}$ coefficient. Odds ratio (OR) estimates and their 95\% confidence interval (CI) were calculated and reported.
The quality of the model was determined by measures of sensitivity, specificity, area under the ROC (Receiver Operating Characteristic) curve, Pseudo $\mathrm{R}^{2}$ (Nagelkerke) and the Hosmer-Lemeshow test. All tests were performed using statistical software (Statistical Package for Social Sciences, 16.0 - SPSS Inc., Chicago, IL, USA.) Results were considered significant if a $\mathrm{p}$-value lower than $5 \%$ was attained $(p<0.05)$.

\section{Results}

This study comprised a sample of 138 individuals under PMT over 6 years, 24 individuals under intensive alcohol use, 26 individuals under moderate alcohol use and 88 individuals who did not or occasionally used alcohol. Group characteristics regarding variables of interest are presented in Table 1. Significant differences between groups were observed in relation to sex, co-habitation status, diabetes, and smoking. However, important variables such as time since APT and number of PMT visits were not significant among the study groups.

Comparative analysis among study groups and times in relation to periodontal clinical parameters is presented in Table 2. Overall, no significant differences were observed regarding the parameters PI, BOP, $\mathrm{PD}$, and $\mathrm{CAL}$ among groups at the baseline (IA $=\mathrm{MA}$ =NA). As a result, groups were determined to be homogeneous after APT. On the other hand, significant differences between NA, MA, and IA groups were observed at the final examination. The IA group exhibited higher mean PI, BOP, PD, and CAL, as well as higher TL (IA > MA > NA). Moreover, at T2, group IA showed significant differences in relation to group MA for all clinical parameters. However, the comparison of MA versus NA did not reveal significant differences for PI and BOP.

The frequency of RP was $46.5 \%$ (reference) in the NA, $57.6 \%$ (crude OR $=1.23 ; 95 \%$ CI $0.83-1.84 ; p=0.222$ ) in the MA and $79.1 \%$ (crude OR $=1.69,95 \%$ CI 1.25 $2.30, p=0.04$ ) in the IA group.

In the univariate analysis, age $>50$ years old $(\mathrm{OR}=1.63$; $95 \%$ CI 1.15-2.31; $p=0.002)$, former smoking (OR $=$ $1.55 ; 95 \%$ CI $1.07-2.24 ; p=0.020)$ and current smokers $(\mathrm{OR}=1.82 ; 95 \%$ CI $1.34-2.46 ; p=0.001)$ were significantly associated with RP (Table 4 ).

Final multivariate logistic regression model for RP, adjusted for all variables of interest, are shown in Table 4. The following variables were significantly associated with RP at T2: age $>50$ years old $(\mathrm{OR}=1.79 ; 95 \% \mathrm{CI}$ $1.42-2.91 ; p=0.002)$, current smoking $(\mathrm{OR}=2.42$; $95 \%$ CI 1.33-4.31; $p=0.001)$, and intensive alcohol use $(\mathrm{OR}=1.96 ; 95 \% \mathrm{CI}: 1.37-2.64 ; p=0.024)$. Interaction between intensive alcohol use and smoking showed higher OR estimate of $3.15(95 \%$ CI $1.29-6.32 ; p=0.012)$ for RP. It is stressed that smokers with intensive alcohol use showed 3 times more chance of presenting PR. 
Table 1: Characteristics of participants by alcohol consumption status at $\mathrm{T} 2$.

\begin{tabular}{|c|c|c|c|c|}
\hline Variables & $\begin{array}{l}\text { None or occasional } \\
\text { alcohol use } \\
\text { (NA) }\end{array}$ & $\begin{array}{l}\text { Moderate } \\
\text { alcohol use } \\
\text { (MA) }\end{array}$ & $\begin{array}{l}\text { Intense } \\
\text { alcohol use } \\
\text { (IA) }\end{array}$ & Total sample \\
\hline Total & $\begin{array}{c}n=88 \\
(64.8 \%)\end{array}$ & $\begin{array}{c}n=26 \\
(18.3 \%)\end{array}$ & $\begin{array}{c}n=24 \\
(16.9 \%)\end{array}$ & $\mathrm{n}=138$ \\
\hline \multicolumn{5}{|l|}{ Sex* } \\
\hline Women & $50(55.7 \%)$ & $15(60.0 \%)$ & $6(32.0 \%)$ & $71(51.5 \%)$ \\
\hline Men & $38(44.3 \%)$ & $11(40.0 \%)$ & $18(68.0 \%)$ & $67(48.5 \%)$ \\
\hline \multicolumn{5}{|l|}{ Age } \\
\hline$\leq 50$ years & $37(42.7 \%)$ & $9(35.6 \%)$ & $14(47.2 \%)$ & $60(43.5 \%)$ \\
\hline$>50$ years & $51(57.3 \%)$ & $17(64.4 \%)$ & $10(52.8 \%)$ & $78(56.5 \%)$ \\
\hline \multicolumn{5}{|l|}{ Family income } \\
\hline$\leq 5 \mathrm{BMS}$ & $31(37.0 \%)$ & $9(40.5 \%)$ & $10(40.5 \%)$ & $57(41.3 \%)$ \\
\hline$>5 \mathrm{BMS}$ & $57(63.0 \%)$ & $13(59.5 \%)$ & $15(59.5 \%)$ & $81(58.7 \%)$ \\
\hline \multicolumn{5}{|l|}{ Educational level } \\
\hline$<8$ years & $40(55.4 \%)$ & $15(38.8 \%)$ & $14(42.1 \%)$ & $69(50.0 \%)$ \\
\hline$\geq 8$ years & $48(44.6 \%)$ & $11(62.2 \%)$ & $10(57.9 \%)$ & $69(50.0 \%)$ \\
\hline \multicolumn{5}{|l|}{ Co-habitation status* } \\
\hline With companion & $60(67.0 \%)$ & $16(74.5 \%)$ & $9(43.7 \%)$ & $85(61.6 \%)$ \\
\hline Without companion & $28(33.0 \%)$ & $10(25.5 \%)$ & $15(58.3 \%)$ & $53(38.4 \%)$ \\
\hline \multicolumn{5}{|l|}{ Number of PMT visits } \\
\hline (mean \pm s.d.) & $6.4( \pm 0.7)$ & $6.5( \pm 0.4)$ & $6.3( \pm 0.5)$ & $6.4( \pm 0.5)$ \\
\hline $\begin{array}{l}\text { Times since APT } \\
{[\text { months }(\text { mean } \pm \text { s.d. })]^{* *}}\end{array}$ & $71.6( \pm 3.2)$ & $72.7( \pm 2.9)$ & $70.2( \pm 2.7)$ & $71.5( \pm 2.9)$ \\
\hline \multicolumn{5}{|l|}{ Diabetes* } \\
\hline Yes & $5(8.4 \%)$ & $3(9.0 \%)$ & $5(12.0 \%)$ & $13(9.4 \%)$ \\
\hline No & $83(91.6 \%)$ & $23(91.0 \%)$ & $19(88.0 \%)$ & $125(90.6 \%)$ \\
\hline \multicolumn{5}{|l|}{ Smoking * } \\
\hline Non-smokers & $67(76.1)$ & $15(57.7)$ & $9(37.5)$ & $91(65.9)$ \\
\hline Former-smokers & $13(14.8)$ & $4(15.4)$ & $5(20.8)$ & $22(15.9)$ \\
\hline Current-smokers & $8(9.1)$ & 7 (26.9) & $10(41.7)$ & $25(18.2)$ \\
\hline $\begin{array}{l}\text { Mean time of alcohol use } \\
\text { [years (mean } \pm \text { s.d) }]^{*}\end{array}$ & NA & $42.2( \pm 13.4)$ & $46.4( \pm 15.2)$ & - \\
\hline
\end{tabular}

${ }^{*}$ Chi-square test $(p<0.05)$; **ANOVA $(p<0.05)$. NA = not applicable; BMS = Brazilian minimum salary/monthly (approximately 300 American dollars).

\section{Discussion}

The present study investigated the association between the frequency of alcohol consumption and RP in individuals on PMT and confirmed the hypothesis of higher alcohol consumption being associated with worse periodontal condition and higher RP and TL. Significant differences between NA, MA, and IA groups were observed at T2. The IA group exhibited higher mean PI, BOP, PD, and CAL, as well as higher TL (IA > MA > NA). Moreover, MA and NA were significantly different only in relation to PI and BOP. It is noteworthy that these findings were more pronounced in smokers.
Conflicting findings regarding the association between alcohol consumption and periodontitis were previously published in the literature, having some studies reporting it as positive $(5-7,9,10)$ while others reporting no association $(23,24)$. Few prospective studies $(5,8,25)$ have evaluated the influence of alcohol on the progression of periodontitis. To our knowledge, no study investigated the effect of alcohol consumption among individuals under PMT.

The mechanisms underlying the association between alcohol consumption and the risk for periodontitis are still unclear. According to the review and meta-analysis 
Table 2: Comparative analysis among study groups and examination times in relation to periodontal clinical parameters.

\begin{tabular}{|c|c|c|c|c|}
\hline $\begin{array}{l}\text { Total sample } \\
\quad(n=142)\end{array}$ & IA $(n=24)$ & MA $(n=26)$ & NA $(n=88)$ & $\begin{array}{c}\mathbf{p} \\
\text { (intergroup } \\
\text { comparisons) }\end{array}$ \\
\hline $\begin{array}{l}\text { Plaque Index }(\mathbf{\%}) * \\
\text { T1 } \\
\text { T2 } \\
\text { p (intragroup comparison) }\end{array}$ & $\begin{array}{c}40.0 \pm 9.5 \mathrm{~A} \\
47.2 \pm 9.1 \mathrm{~A} \\
0.010\end{array}$ & $\begin{array}{c}38.3 \pm 9.8 \mathrm{~A} \\
43.0 \pm 10.3 \mathrm{~B} \\
0.805\end{array}$ & $\begin{array}{c}39.2 \pm 9.7 \mathrm{~A} \\
40.4 \pm 10.4 \mathrm{~B} \\
0.517\end{array}$ & $\begin{array}{l}0.988 \\
0.014\end{array}$ \\
\hline $\begin{array}{l}\text { Mean BOP } \\
\text { T1 } \\
\text { T2 } \\
\text { p (intragroup comparison) }\end{array}$ & $\begin{array}{c}27.3 \pm 12.1 \mathrm{~A} \\
35.2 \pm 11.2 \mathrm{~A} \\
0.023\end{array}$ & $\begin{array}{c}26.6 \pm 10.9 \mathrm{~A} \\
30.8 \pm 8.1 \mathrm{~B} \\
0.030\end{array}$ & $\begin{array}{l}27.4 \pm 9.7 \mathrm{~A} \\
27.9 \pm 9.1 \mathrm{~B} \\
0.552\end{array}$ & $\begin{array}{l}0.941 \\
0.013\end{array}$ \\
\hline $\begin{array}{l}\text { Mean PD (mm) }{ }^{* *} \\
\text { T1 } \\
\text { T2 } \\
\text { p (intragroup comparison) }\end{array}$ & $\begin{array}{c}2.9 \pm 0.6 \mathrm{~A} \\
3.8 \pm 0.5 \mathrm{~A} \\
0.001 \\
\end{array}$ & $\begin{array}{c}2.8 \pm 0.9 \mathrm{~A} \\
3.2 \pm 0.4 \mathrm{~B} \\
0.001 \\
\end{array}$ & $\begin{array}{l}2.9 \pm 0.6 \mathrm{~A} \\
2.8 \pm 0.5 \mathrm{C} \\
0.080\end{array}$ & $\begin{array}{c}0.788 \\
<0.001\end{array}$ \\
\hline $\begin{array}{l}\text { Mean CAL (mm) })^{* *} \\
\text { T1 } \\
\text { T2 } \\
\text { p (intragroup comparison) }\end{array}$ & $\begin{array}{l}3.4 \pm 0.7 \mathrm{~A} \\
4.2 \pm 0.6 \mathrm{~A} \\
0.000\end{array}$ & $\begin{array}{c}3.3 \pm 1.6 \mathrm{~A} \\
3.9 \pm 0.5 \mathrm{~B} \\
0.000\end{array}$ & $\begin{array}{l}3.1 \pm 1.4 \mathrm{~A} \\
3.5 \pm 0.7 \mathrm{C} \\
<0.001\end{array}$ & $\begin{array}{c}0.565 \\
<0.001\end{array}$ \\
\hline $\begin{array}{l}\text { PD } \geq 5 \text { mm (\% sites) }{ }^{* *} \\
\text { T1 } \\
\text { T2 } \\
\text { p (intragroup comparison) }\end{array}$ & $\begin{array}{l}1.7 \pm 0.6 \mathrm{~A} \\
4.8 \pm 0.4 \mathrm{~A} \\
0.001\end{array}$ & $\begin{array}{l}1.9 \pm 0.5 \mathrm{~A} \\
4.4 \pm 0.7 \mathrm{~B} \\
\quad<0.001\end{array}$ & $\begin{array}{l}1.7 \pm 0.8 \mathrm{~A} \\
3.7 \pm 0.4 \mathrm{C} \\
<0.001\end{array}$ & $\begin{array}{c}0.446 \\
<0.001\end{array}$ \\
\hline $\begin{array}{l}\text { CAL } \geq \mathbf{5} \mathbf{~ m m}(\% \text { sites) } \\
\text { T1 } \\
\text { T2 } \\
\text { p (intragroup comparison) }\end{array}$ & $\begin{array}{c}9.6 \pm 3.1 \mathrm{~A} \\
13.9 \pm 2.9 \mathrm{~A} \\
0.001\end{array}$ & $\begin{array}{c}9.8 \pm 3.3 \mathrm{~A} \\
12.1 \pm 3.2 \mathrm{~B} \\
0.013\end{array}$ & $\begin{array}{l}9.5 \pm 3.1 \mathrm{~A} \\
9.2 \pm 3.3 \mathrm{C} \\
0.560\end{array}$ & $\begin{array}{c}0.911 \\
<0.001\end{array}$ \\
\hline $\begin{array}{l}\text { Lost teeth }^{* *} \\
\text { T1 } \\
\text { T2 } \\
\text { p (intragroup comparison) }\end{array}$ & $\begin{array}{c}3.9 \pm 0.8 \mathrm{~A} \\
5.6 \pm 1.8 \mathrm{~A} \\
0.001\end{array}$ & $\begin{array}{l}4.0 \pm 1.2 \mathrm{~A} \\
4.9 \pm 2.2 \mathrm{~B} \\
0.033\end{array}$ & $\begin{array}{c}4.0 \pm 0.9 \mathrm{~A} \\
4.5 \pm 1.1 \mathrm{C} \\
0.062\end{array}$ & $\begin{array}{l}0.895 \\
0.006\end{array}$ \\
\hline
\end{tabular}

from Wang et al. (10), the following biological plausibility explanations are listed: "(i) periodontal disease is associated with impaired neutrophil phagocytosis. Thus, alcohol could weaken neutrophil function, leading to bacterial overgrowth and increasing bacterial penetration, which could result in periodontal inflammation; (ii) alcohol intake could result in toxic effects on periodontium and may make a reduction in monocyte production of inflammatory cytokines which are possibly beneficial to microbial proliferation; (iii) the inflammatory cytokines such as TNFa, IL-1 and IL-6 released by monocyte in gingival crevice have been proved to be interrelated in periodontitis development."

Based on our previous PMT studies $(12,13)$, we believe that recall visits at short intervals may compromise adherence to maintenance programs over the years for different reasons. In the present study, we established a range of recall interval times being the one that the majority of our cohort participants followed during PMT without further worsening the periodontal clinical con- dition. This interval time (up to 12 months) was yet considered reasonable in clinical practice. Rosén et al. (26) suggested that recall intervals extended to a year might be acceptable for the purpose of reducing periodontal disease progression in individuals with a history of limited or moderate susceptibility to the disease.

The present study showed that, in addition to the intensive alcohol use, other variables were also significantly retained in the final multivariate model for RP: age $>50$ years old, current smoking and the interaction between intensive alcohol use and current smoking.

Age may be a risk indicator for periodontal disease in some populations. However, aging may be related to increased attachment loss and not to periodontitis (13).

Recent systematic reviews $(27,28)$ have demonstrated strong association between smoking and the risk of periodontal attachment loss, as well as bone and tooth loss. In addition, studies have shown incremental OR estimates for the occurrence of periodontitis when the smoking dose-exposure was evaluated $(4,21)$. Studies have repor- 
Table 3: Distribution of independent variables according to the recurrence of periodontitis at T2.

\begin{tabular}{|c|c|c|c|c|c|c|}
\hline \multirow[t]{2}{*}{$\begin{array}{l}\text { Variables } \\
(\mathrm{n}=138)\end{array}$} & \multicolumn{2}{|c|}{$\begin{array}{l}\text { Recurrence of } \\
\text { Periodontitis } \\
(n=75 ; 54.3 \%)\end{array}$} & \multicolumn{2}{|c|}{$\begin{array}{l}\text { No Recurrence of } \\
\text { Periodontitis } \\
(n=63 ; 45.7 \%)\end{array}$} & \multirow[t]{2}{*}{ Crude OR (95\% CI) } & \multirow[t]{2}{*}{$p^{*}$} \\
\hline & $\mathbf{n}$ & $\%$ & $\mathbf{n}$ & $\%$ & & \\
\hline \multicolumn{7}{|l|}{ Alcohol Use } \\
\hline None or occasional $(\mathrm{n}=88)$ & 41 & 46.5 & 47 & 53.5 & - & \\
\hline Moderate $(n=26)$ & 15 & 57.6 & 11 & 42.3 & $1.23(0.83-1.84)$ & 0.222 \\
\hline Intense $(n=24)$ & 19 & 79.1 & 5 & 20.9 & $1.69(1.25-2.30)$ & $\mathbf{0 . 0 0 4}$ \\
\hline \multicolumn{7}{|l|}{ Smoking status } \\
\hline Non-smokers $(\mathrm{n}=91)$ & 40 & 43.9 & 51 & 56.1 & - & \\
\hline Former-smokers $(\mathrm{n}=22)$ & 15 & 68.2 & 7 & 31.8 & $1.55(1.07-2.24)$ & 0.020 \\
\hline Current-smokers $(n=25)$ & 20 & 80.0 & 5 & 20.0 & $1.82(1.34-2.46)$ & $\mathbf{0 . 0 0 1}$ \\
\hline \multicolumn{7}{|l|}{ Sex } \\
\hline Women $(\mathrm{n}=71)$ & 41 & 54.7 & 30 & 47.6 & - & \\
\hline $\operatorname{Men}(n=67)$ & 34 & 45.3 & 33 & 52.4 & $0.87(0.64-1.19)$ & 0.250 \\
\hline \multicolumn{7}{|l|}{ Age } \\
\hline$\leq 50$ years $(n=60)$ & 24 & 32.0 & 36 & 57.1 & - & \\
\hline$>50$ year $(n=78)$ & 51 & 68.0 & 27 & 42.9 & $1.63(1.15-2.31)$ & 0.002 \\
\hline \multicolumn{7}{|l|}{ Family income } \\
\hline$\leq 5 \mathrm{BSM}^{\dagger}(\mathrm{n}=57)$ & 32 & 42.7 & 25 & 39.7 & - & \\
\hline$>5 \mathrm{BSM}^{\dagger}(\mathrm{n}=81)$ & 43 & 57.3 & 38 & 60.3 & $1.05(0.77-1.43)$ & 0.032 \\
\hline \multicolumn{7}{|l|}{ Educational level } \\
\hline$<8$ years $(\mathrm{n}=69)$ & 40 & 53.3 & 29 & 46.0 & - & \\
\hline$\geq 8$ years $(n=69)$ & 35 & 46.7 & 34 & 54.0 & $1.14(0.84-1.55$ & 0.467 \\
\hline \multicolumn{7}{|l|}{ Co-habitation status } \\
\hline Without companion $(\mathrm{n}=53)$ & 28 & 37.3 & 25 & 39.7 & - & \\
\hline With companion $(\mathrm{n}=85)$ & 47 & 62.7 & 38 & 60.3 & $0.95(0.69-1.31)$ & 0.011 \\
\hline \multicolumn{7}{|l|}{ Diabetes } \\
\hline Yes $(n=13)$ & 7 & 9.3 & 6 & 9.5 & - & \\
\hline No $(n=125)$ & 68 & 90.7 & 57 & 90.5 & $1.98(0.58-1.67)$ & 0.064 \\
\hline
\end{tabular}

*Chi-square test. Significant p-values are shown in bold.

$\dagger \mathrm{BMS}=$ Brazilian minimum salary/monthly (approximately 300 American dollars). 
Table 4: Final logistic regression model for the recurrence of periodontitis at T2.

\begin{tabular}{|l|c|c|}
\hline Variables & Odds ratio (95\% IC) & $p$ \\
\hline Age $>50$ years & $1.79(1.42-2.91)$ & 0.002 \\
\hline Current Smoking & $2.42(1.33-4.31)$ & 0.001 \\
Intensive alcohol use & $1.96(1.37-2.64)$ & 0.024 \\
\hline Interaction between alcohol use and current smokers & $3.15(1.29-6.32)$ & 0.012 \\
\hline
\end{tabular}

Homer-Lemeshow test $(p=0.041)$; Pseudo $\mathrm{R}^{2}=43.6 \%$; area under the $\mathrm{ROC}$ curve $=0.871$; Sensitivity $=0.749$; Specificity $=0.871$.

ted a high prevalence of smokers among alcohol users $(4,7,28,29)$. Findings from the present study confirms this statement showing a high prevalence of smokers and a strong association between smoking and periodontitis. It was also demonstrated in the present study that the association between periodontitis and alcohol use was independent from smoking. Similar findings were also reported $(4,7)$.

It is important to highlight that methodological issues may have significantly influenced the conflicting results of the association between alcohol and periodontitis previously presented in the literature $(4,5)$. Some studies presented small samples and great variability in the definition of alcohol dose-exposure, including different cut-off points for the amount and frequency of alcohol consumption $(23,24)$. Others presented less robust definitions of periodontitis $(5,6)$. Methods of measurement of alcohol exposure levels and dependence are complex and prone to information biases $(4,20)$. However, the use of AUDIT and CAGE questionnaires can minimize these biases. AUDIT was developed under the supervision of WHO (20) and it is composed of 10 questions (three questions about the consumption of alcoholic beverages, four questions of its dependency, and three questions about problems related to its consumption. CAGE is validated in Brazil (19) and it is composed by four questions. CAGE presents a specificity of $83 \%$ and a sensitivity of $88 \%$ when the cut-off point of two positive answers was adopted to define alcoholic beverages.

Limitations can be attributed to the present study as the measurements of alcohol consumption is subject to bias information, as well as the small sample of individuals with RP in the final multivariate analysis. However, the 6-year follow-up period, the prospective design, the use of a structured questionnaire, the adjustment for confounding variables (mainly age), the standardization of the procedures for periodontal treatment and maintenance therapy may minimize the impact of these limitations. IA individuals undergoing PMT presented worse periodontal condition, high rates of RP and TL when compared to NA individuals. Additionally, the interaction between intensive alcohol use and smoking significantly increased the risk for RP. This finding demonstrated the influence of intensive alcohol use during PMT in maintaining a good periodontal status.

\section{References}

1. Tonetti MS, Greenwell H, Kornman KS. Staging and grading of periodontitis: Framework and proposal of a new classification and case definition. J Periodontol. 2018;89:S159-72.

2. Kinane DF, Stathopoulou PG, Papapanou PN. Periodontal diseases. Nature Rev Dis Primers. 2017;3:17038.

3. Beaglehole R, Bonita R. Alcohol: a global health priority. Lancet. 2009;27:2173-4.

4. Lages EPL, Costa FO, Lages EMB, Lorentz TCM, Soares RV, Cortelli JR. Risk variables in the association between frequency of alcohol consumption and periodontitis. J Clin Periodontol. 2012;39:115-22.

5. Okomoto Y, Tsuboi S, Suzuki S, Nakagaki H, Ogura Y, Maeda K, et al. Effects of smoking and drinking habits on the incidence of periodontal disease and tooth loss among Japanese males: a 4-yr longitudinal study. J Periodontol Res. 2006;41:560-6.

6. Shimazaki Y, Saito T, Kiyohara Y, Kato I, Kubo M, Lida M, et al. Relationship between drinking and periodontitis: the Hisayama study. J Periodontol. 2005;76:1534-41.

7. Tezal M, Grossi SG, Ho AW, Genco RJ. Alcohol consumption and periodontal disease The Third National Health and Nutrition Examination Survey. J Periodontol. 2004;17:484-8.

8. Wagner MC, Haas AN, Oppermann RV, Rosing CK, Albandar JM, Susin, C. Effect of Alcohol Consumption on Clinical Attachment Loss Progression in an Urban Population From South Brazil: A 5-Year Longitudinal Study. J Periodontol. 2017;88:1271-80.

9. Gay IC, Tran DT, Paquette DW. Alcohol intake and periodontitis in adults aged $\geq 30$ years: NHANES 2009-2012 J Periodontol. 2018;89:625-34.

10. Wang J, Lv J, Wan W, Jiang X. Alcohol consumption and risk of periodontitis: a meta-analysis. J Clin Periodontol. 2016;43:572-83.

11. Axelsson P, Nystrom B, Lindhe, J. The long-term effect of a plaque control program on tooth mortality, caries and periodontal disease in adults: Results after 30 years of maintenance. J Clin Periodontol. 2004;31:749-57.

12. Lorent, TCM, Cota LOM, Cortelli JR, Vargas AMD, Costa FO. Prospective study of complier individuals under periodontal maintenance therapy: analysis of clinical periodontal parameters, risk predictors and the progression of periodontitis. J Clin Periodontol. 2009;36:58-67.

13. Costa FO, Cota LOM, Cortelli JR, Cortelli SC, Cyrino RM, Lima APL. Surgical and non-surgical procedures associated with recurrence of periodontitis in periodontal maintenance therapy: 5-year prospective study. PLoS ONE. 2015;10:e0140847.

14. Lee CT, Huang HY, Sun TC, Karimbux N. Impact of patient compliance on tooth loss during supportive periodontal therapy: a systematic review and meta-analysis. J Dental Res. 2015; 94:777-86.

15. McCraken G, Asuni A, Ritchie M, Vernazza C, Heasman P. Failing to meet the goals of periodontal recall programs. What next? Periodontol. 2000 2017;75:330-52.

16. Manresa C, Sanz-Miralles EC, Twigg J, Bravo M. Supportive pe- 
riodontal therapy (SPT) for maintaining the dentition in adults treated for periodontitis. Cochrane Database Syst Rev. 2018;1:CD009376.

17. Armitage GC. Development of a classification system for periodontal diseases and conditions. Ann Periodontol. 1999;4:1-6.

18. Mayfield D, Mcleod G, Hall P. The CAGE questionnaire: validation of a new alcoholism screening instrument. Am J Psych. 1974;131:1121-3.

19. Masur J, Monteiro MG. Validation of the "CAGE" alcoholism screening test in a Brazilian psychiatric inpatient hospital setting. Braz J Med Biol Res. 1983;16:215-8.

20. Saunders JB, Aasland OG, Babor TF, De la Fuente JR, Grant M. Development of the alcohol use disorders identification test (AUDIT): WHO Collaborative project on early detection of persons with harmful alcohol consumption.-II Addiction. 1993;88:791-804.

21. Tomar SL, Asma S. Smoking-attributable periodontitis in the United States, findings from NHANES III National Health and Nutrition Examination Survey. J Periodontol. 2000;71:743-51.

22. Matuliene G, Studer R, Lang NP, Schmidlin K, Pietursson BE, Salvi GE, et al. Significance of periodontal risk assessment in the recurrence of periodontitis and tooth loss. J Clin Periodontol. 2010;37:1919 .

23. Bouchard P, Boutouyrie P, Mattout C, Bourgeois D. Risk assessment for severe clinical attachment loss in an adult population. J Periodontol. 2006;77:479-89.

24. Jansson L. Association between alcohol consumptions and dental health. J Clin Periodontol. 2008;35:379-84.

25. Hach M, Holm-Pedersen P, Adegboye AR, Avlund K. The effect of alcohol consumption on periodontitis in older Danes. Int J Dental Hyg. 2015;13:261-7.

26. Rosén B, Olavi G, Badersten A, Rönström A, Söderholm G, Egelberg J. Effect of different frequencies of preventive maintenance treatment on periodontal conditions 5-year observations in general dentistry patients. J Clin Periodontol. 1999;26:225-33.

27. Vieira TR, Martins CC, Cyrino RM, Azevedo AMO, Cota LOM, Costa FO. Effects of smoking on tooth loss among individuals under periodontal maintenance therapy: a systematic review and meta-analysis. Cad Saude Publica. 2018;34:e0024918.

28. Ryder MI, Couch ET, Chaffee BW. Personalized periodontal treatment for the tobacco- and alcohol-using patient. Periodontol 2000. 2018;78:30-46.

29. Suwama K, Yoshihara A, Watanabe R, Stegaroiu R, Shibata S, Miyazaki $\mathrm{H}$. Relationship between alcohol consumption and periodontal tissue condition in community-dwelling elderly Japanese. Gerodontol 2018. [Epub ahead of print]

\section{Availability of Data and Materials}

The authors consent to the use of this article and its data without res-triction, provided that the original authors are cited. Data are available from the corresponding author at a reasonable request.

\section{Conflict of Interest}

The authors declare no conflicts of interest. 